\title{
Correction to: Identification of two different chemosensory pathways in representatives of the genus Halomonas
}

Ana Florencia Gasperotti ${ }^{1}$, María Victoria Revuelta ${ }^{2}$, Claudia Alicia Studdert ${ }^{3}$ and María Karina Herrera Seitz ${ }^{1 *}$

\section{Correction}

Following the publication of this article [1], the authors noticed that Fig. 3 was missing. In that figure, one of the numbers corresponding to the Halomonas chemoreceptors was missing: namely, chemoreceptor 07070. The correct version of Fig. 3 has been included in this Correction.

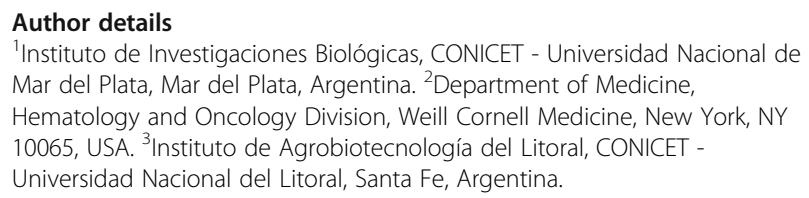

Received: 23 May 2018 Accepted: 23 May 2018

Published online: 07 June 2018

\section{Reference}

1. Gasperotti AF, et al. BMC Genomics. 2018;19:266.

\footnotetext{
*Correspondence: khseitz@mdp.edu.ar

${ }^{1}$ Instituto de Investigaciones Biológicas, CONICET - Universidad Nacional de

Mar del Plata, Mar del Plata, Argentina

Full list of author information is available at the end of the article
} 


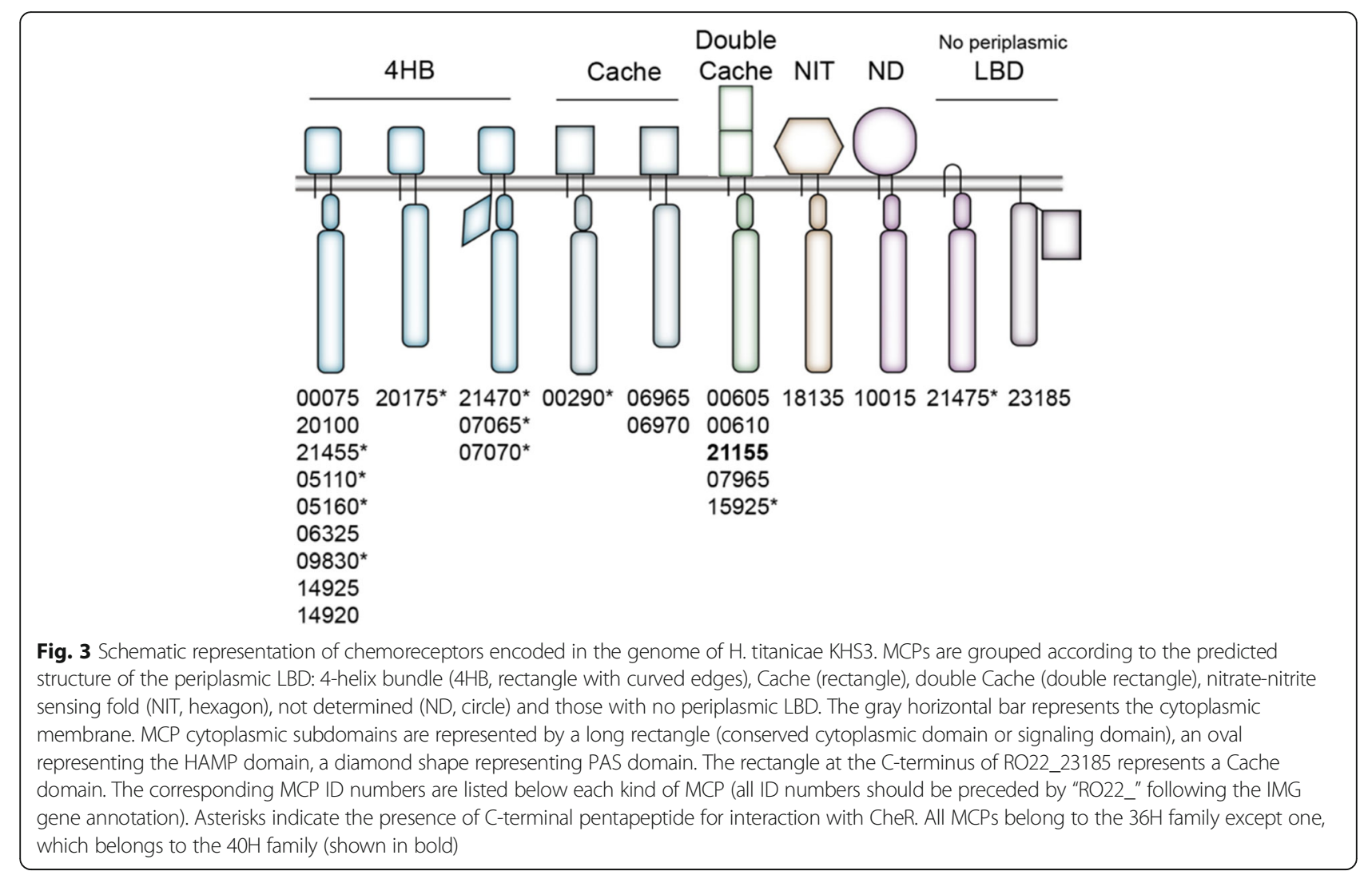

